\title{
A case-control study of transient global amnesia
}

\author{
MARIO GUIDOTTI,* NICOLETTA ANZALONE,** ALBERTO MORABITO, $\dagger$ \\ GIANLUCA LANDI* \\ From the Neurological Clinic, ${ }^{*}$ and the Institute of Medical Statistics and Biometry, $\dagger$ University of Milan, Milan, \\ Italy
}

SUMMARY To evaluate risk factors and prognosis of transient global amnesia (TGA), three groups of 30 subjects each affected respectively by: (1) first-ever TGA; (2) first-ever transient ischaemic attack (TIA); (3) depressive neurosis, were compared. Prevalence of cerebrovascular risk factors was similar in patients with TGA and TIA, but significantly lower in the third group. CT showed more hypodense lesions in TIA patients than in those with TGA. In a mean follow-up of 36 months, five TGA patients experienced a TIA and three others had recurrence of TGA, but none suffered stroke or myocardial infarction. In the TIA group, four had recurrence of TIA, two suffered a stroke and two others a myocardial infarction, whereas none had TGA attacks. None of the patients of the third group had any ischaemic event during follow-up. The similar prevalence of risk factors, but the different prognosis between TGA and TIA patients, suggest that TGA is an ischaemic event, probably not triggered by thromboembolism but by a different, possibly vasospastic, mechanism.

Although transient global amnesia may occur in association with several morbid conditions, ${ }^{1-6}$ most authors have attributed this syndrome to reversible ischaemia affecting the inferomedial part of the temporal lobes. ${ }^{7-10}$ This view is supported by the high prevalence of cerebrovascular risk factors often observed in these patients. ${ }^{12}$ However, most studies lacked data from suitable control groups.

A recent case study of TGA concluded that this condition is closely linked to cerebrovascular disease, but its results were probably influenced by the unusually frequent prevalence of previous cerebrovascular attacks in the series. ${ }^{13}$

The prognosis of TGA is generally considered benign as most authors report a favourable long-term outcome in these patients. ${ }^{14-16}$ This fact is at variance with the assumption that TGA is a manifestation of cerebrovascular ischaemia, which carries a serious prognosis.

To determine the prevalence of cerebrovascular risk factors and the prognosis of TGA, we studied a series of patients with this condition, and compared them with a group of patients with their first TIA and with another group with only minor psychiatric symptoms.

Address for reprint requests: M Guidotti, MD, Neurological Clinic II, Ospedale Policlinico, via F. Sforza, 3520122 Milano, Italy.

Received 10 May 1988 and in revised form 10 October 1988. Accepted 17 October 1988

\section{Patients and methods}

From June 1979 to May 1986 we observed a consecutive series of 30 patients presenting with their first-ever attack of TGA. All these patients were seen during the TGA attack at the emergency room by a member of our neurological staff. Strict criteria were adopted for diagnosis, namely: spontaneous acute onset of recent memory loss; preservation of consciousness and identity; demonstrated inability to retain new memories; regression of symptoms within 24 hours, with only persistent amnesia for the period of the attack. No patient had focal neurological deficits during TGA event. Patients with a history of recent head trauma, alcohol or drug intoxication, or psychosis were excluded from the study, whereas patients with previous TIA and stroke were not excluded. All patients underwent neurological and cardiological examinations as well as routine blood tests, ECG, EEG, continuous-wave (CW) Doppler study and CT.

The events and the patients' activities just antedating the TGA attack were recorded. In all patients a prospective follow-up was conducted by the same neurologists who observed the patients during the TGA attack, until June 1987.

\section{Control groups}

The (Group 1) patients were compared with two other groups of age- ( \pm 3 years) and sex-matched patients affected by transient ischaemic attacks (Group 2) or by depressive neurosis (Group 3), the latter diagnosed according to criteria consistent with DSM III. ${ }^{17}$

Group 2 patients had experienced their first-ever TIA within the previous month. Transient ischaemic attacks were 
defined as a period of focal cerebral dysfunction produced by ischaemic vascular mechanisms, lasting less than 24 hours. Diagnosis of arterial territory distribution followed established criteria. ${ }^{18}$

Those of the third group were outpatients, and the chronic depressive disorder was defined "minor". They were not selected on the basis of previous TIA or TGA episodes. This fact makes these subjects representative of the general population as far as it concerns the risk of cerebrovascular disease. The presence or absence of cerebrovascular risk factors was assessed as follows: (1) hypertension: the repeated finding of systolic blood pressure higher than 160 $\mathrm{mm} \mathrm{Hg}$, diastolic blood pressure more than $90 \mathrm{~mm} \mathrm{Hg}$, or regular use of antihypertensive drugs; (2) hyperlipidaemia: fasting serum cholesterol over $215 \mathrm{mg} / \mathrm{dl}$ or triglycerides higher than $170 \mathrm{mg} / \mathrm{dl}$ (the 90th percentiles of a control population in our laboratory); (3) diabetes mellitus: fasting blood sugar higher than $140 \mathrm{mg} / \mathrm{dl}$ or therapy with hypoglycaemic drugs; (4) smoking: more than 10 cigarettes daily; and (5) cardiac disease: past or presence evidence of ischaemic heart disease, heart failure, significant dysrhythmias, valvular disease.

In the two control groups, case histories were collected and the same clinical tests done, except for CW-Doppler, EEG and CT, which were not performed in Group 3.

All control patients were also followed-up, and particular attention was paid to occurrence of cerebral ischaemia, myocardial infarction or TGA.

Treatments assigned to the three groups were also recorded.

\section{Statistical analysis}

To analyse the prevalence of risk factors, odds ratio were calculated, and their confidence limits following the Miettinen procedure. ${ }^{19}$ The significance test of odds ratio were calculated by the chi-square for two by two table.

The frequency of detectable abnormalities demonstrated by CT in the three groups was compared using the chi-square, whereas to evaluate the time of onset of events during followup, product-limit survival curves were producted; and their significance tested by the log-rank test. ${ }^{20}$
Table 2 CT results

\begin{tabular}{llc}
\hline & Normal & Hypodensity \\
\hline Group 1 (TGA) & $29(96 \cdot 7 \%)$ & $1(3.3 \%)$ \\
Group 2 (TIA) & $23(76 \cdot 7 \%)$ & $7(23.3 \%)$ \\
Group 3 & & not done \\
\hline
\end{tabular}

$\chi^{2}=5.192 \quad \mathrm{p}<0.05$

\section{Results}

\section{Group 1 (TGA)}

Patients' age ranged from 42 to 81 years (mean: 60.4). 13 were males $(43 \%)$, with a mean age of 56.5 years, and 17 females (mean age: 63.7).

History. Most patients were in good health at the time of their TGA. Three subjects had experienced previous TIA in the carotid territory, Four suffered from migraine, none had epilepsy. 27 patients $(90 \%)$ had one or more risk factors for cerebrovascular disease (table 1).

Factors potentially triggering TGA attack were identified in 26 patients; 21 had their episode during exertion, whereas five during emotional stress.

Clinical and instrumental findings. Neurological examination was normal in all patients after their attack. EEG was normal in $28(93 \%)$, and in two cases it showed left temporal slow waves, without epileptic discharges.

CT (table 2) was normal in 28 cases (93\%); in one patient it demonstrated a right deep hemispheric hypodensity, and in another diffuse cerebral atrophy. These two patients had no history of previous TIA, or of migraine.

CW-Doppler examination revealed absence of haemodinamically significant stenoses in all patients. Outcome. Within a mean follow-up of 39.6 months

Table 1 Cerebrovascular risk factors. Odds ratio and 95\% confidence limits

\begin{tabular}{|c|c|c|c|c|c|}
\hline & $\begin{array}{l}\text { Group 1 } \\
(n=30)\end{array}$ & $\begin{array}{l}\text { Group } 2 \\
(n=30)\end{array}$ & $\begin{array}{l}\text { Group } 3 \\
(n=30)\end{array}$ & $\begin{array}{l}\text { Odds ratio } \\
\text { Group } 1 \text { vs } 2\end{array}$ & $\begin{array}{l}\text { Odds ratio } \\
\text { Group } 1 \text { vs } 3\end{array}$ \\
\hline Hypertension & 14 & 14 & 5 & $\begin{array}{c}1 \\
(-----) \\
p=1\end{array}$ & $\begin{array}{c}4.37 \\
(1.37-13.93) \\
p=0.013\end{array}$ \\
\hline Smoking & 8 & 8 & 3 & $\begin{array}{c}1 \\
(------) \\
p=1\end{array}$ & $\begin{array}{c}3.27 \\
(0.81-13.17) \\
p=0.1\end{array}$ \\
\hline Hyperlipidemia & 10 & 9 & 5 & $\begin{array}{c}1.16 \\
(0.39-3.46) \\
p=0.78\end{array}$ & $\begin{array}{c}2.5 \\
(0.75-8.34) \\
p=0.14\end{array}$ \\
\hline Diabetes mellitus & 3 & 8 & 1 & $\begin{array}{c}0.30 \\
(0.07-1.23) \\
p=0.1\end{array}$ & $\begin{array}{c}3.22 \\
(0.35-29 \cdot 53) \\
p=0.30\end{array}$ \\
\hline Cardiopathy & 7 & 11 & 1 & $\begin{array}{c}0.52 \\
(0.17-1.60) \\
p=0.26\end{array}$ & $\begin{array}{c}8.8 \\
(1.35-57.44) \\
p=0.02\end{array}$ \\
\hline
\end{tabular}


Table 3 Results of survival curve analysis

\begin{tabular}{|c|c|c|}
\hline & $\begin{array}{l}\text { Group } 1 \\
(T G A)\end{array}$ & vs $\begin{array}{l}\text { Group } 2 \\
(T I A)\end{array}$ \\
\hline $\begin{array}{l}\text { TIA } \\
\text { "Major" ischaemic events } \\
\text { (stroke and myocardial } \\
\text { infarction) }\end{array}$ & $\begin{array}{l}x^{2}=0 \cdot 10 \\
x^{2}=4 \cdot 400\end{array}$ & $\begin{array}{l}(p=\text { n.s. }) \\
(p<0.04)\end{array}$ \\
\hline TGA & $\chi^{2}=2 \cdot 809$ & $(p=$ n.s. $)$ \\
\hline
\end{tabular}

(range: 13-96), 22 patients (73\%) remained asymptomatic. Five patients $(16 \%)$ presented TIAs, four in the carotid artery territory (three had single attack, whereas one had multiple episodes), and one in the vertebrobasilar territory.

None of the patients with previous TIA developed TGA or any ischaemic attack during the follow-up.

Two patients with TIA had suffered previous TIAs in the same territory. Three patients $(10 \%)$ had recurrence of TGA, but none experienced stroke or myocardial infarction, and none died during followup.

Group 2 (TIA)

None of these subjects had a history of previous TGA. Twenty-nine patients had at least one cerebrovascular risk factor (table 1).

Eleven patients had their attacks in a carotid artery distribution, 13 in the vertebrobasilar territory, whereas the distribution of the attack remained undeterminated in six cases.

CT was normal in 23 cases $(77 \%)$, whereas it demonstrated hypodense hemispheric lesions in seven patients.

Among patients with carotid territory attacks, six had ipsilateral stenosis on CW-Doppler examination. No lesions were found in the other patients. Angiography was performed in 16 patients, and in all cases it confirmed the Doppler findings, without false positives or negatives.

Outcome. Within a mean follow-up of 36 months (range: $12-80), 22$ patients $(73 \%)$ remained asymptomatic. Four patients had recurrence of TIA, two (7\%) had a stroke in the previously symptomatic carotid territory, and two others $(7 \%)$ had a myocardial infarction. No patients had TGA during followup. No patients died during follow-up.

\section{Group 3 (Depressive neurosis)}

None of these patients had a previous history of ischaemic cerebral attacks. $14(47 \%)$ presented at least one atherosclerotic risk factor (table 1).

Outcome. In a mean follow-up of 35 months (range: 12-68), no patients experienced cerebrovascular attacks, myocardial infarction or TGA. All patients were alive at the end of the follow-up.

\section{Discussion}

In this study we have compared a consecutive series of patients with first TGA episode with a group of patients with definite transient cerebral ischaemia and with a third group of subjects representative of the general population as far as concerns their risk of cerebrovascular disease. Accordingly, in TGA patients we have found a low incidence of prior cerebrovascular episodes, as reported in most studies, ${ }^{420} 21$ although it was at variance with data from other reports, which could have selected their patients in some way.

Nonetheless our results show that patients with TGA have a prevalence of risk factors similar to those with TIA, and different from the third group (depressive neurosis). On the contrary, the prognosis in TGA patients were similar to those with depressive neurosis regarding major vascular events, but different from the TIA group. These data are in agreement with those reported in the series of patients with "pure" TGA, ${ }^{1421}$ without associated neurological sign.

On the other hand, $17 \%$ of TGA patients experienced TIA during follow-up, and $10 \%$ had recurrence of TGA. These findings may offer some clue as to the pathogenesis of TGA, since the high incidence of TIAs during follow-up (slightly higher than in the TIA group) suggests a further link between this condition and an ischaemic pathogenesis.

One possible explanation of the apparent paradox of the absence of "serious" episodes, as opposed to a "normal" incidence of transitory events, is that TGA represents an ischaemic episode not caused by vas cular occlusion due to microemboli arising from atheromatous lesions. To support this, negative angiographic and Duplex examinations $\mathrm{s}^{223}$ are often seen in TGA; and also in our patients all the Doppler examinations excluded stenotic lesions. In agreement with this, we have observed a similar prognosis, characterised by the recurrence of TIA but not of stroke or myocardial infarction, in a group of patients with reversible ischaemic attacks and completely negative angiograms. ${ }^{24}$

An alternative cause of ischaemia might be a vasomotor disturbance, and this hypothesis, suggested in the past, has been recently taken up again by Hinge et $\mathrm{al}^{\mathrm{l}^{4}}$ on the basis of the favourable prognosis observed in a large study of TGA cases.

Moreover, this pathogenetic hypothesis is supported by the often-reported association between TGA and migraine. ${ }^{25-27}$ Unlike migraine, which is prevalent in young adults, the occurrence of TGA in elderly patients with cerebrovascular risk factors would suggest that vasomotor phenomena may give rise to TGA in the presence of some impairment of cerebral circulation, probably involving microvessels. In fact, 
the elevated presence of risk factors for atherosclerosis leads one to hypothesise a vascular involvement, even if the large arteries are not affected as shown by our CW-Doppler results.

Even taking into account that the population examined here was not as large as that in other studies on TGA, we hold that the homogeneity of the groups studied and the statistical significance obtained give our results reliability and legitimise several points made.

In conclusion, the occurrence of a TGA episode without other neurological deficit in patients without histories of vascular pathology should be considered benign and does not seem to warrant antithrombotic therapy, even if an eventual reassessment of atherosclerotic risk factors may appear appropriate.

\section{References}

1 Gilbert GJ. Transient global amnesia: manifestation of medical temporal epilepsy. Clin electroencephalogr 1978;9:147-52.

2 Caplan L, Chedru F, Lhermitte F, Maynan CL. Transient global amnesia and migraine. Neurology 1981;31:1167-70.

3 Deisenhammer E. Transient global amnesia as an epileptic manifestation. J Neurol 1981;225:289-92.

4 Lisak RP, Zimmerman RA. Transient global amnesia due to a dominant hemispheric tumour. Arch Neurol 1977;34:317-8.

5 Findler G, Feinsod M, Lijovetzky G, Hodani M. Transient global amnesia associated with a single metastasis in the non-dominant hemisphere. J Neurosurg 1983;58:303-5.

6 Hartley T, Heilman K, Garcia-Bengochea F. A case of transient global amnesia due to a pituitary tumor. Neurology 1974; 24:998-1000.

7 Jensen TS, de Fine Olivarius B. Transient global amnesia as a manifestation of cerebral ischemia. Acta Neurol Scand 1980; 61:115-24.

8 Mathew N, Meyer JS. Pathogenesis and natural history of transient global amnesia. Stroke 1974;5:303-11.

9 Jensen TS, de Fine Olivarius B. Transient global amnesia: its clinical and pathophysiological basis and prognosis. Acta
Neurol Scand 1981;63:220-30.

10 Heathfield KWG, Croft PB, Swash $M$. The syndrome of transient global amnesia. Brain 1973;96:729-36.

11 Fisher CM. Transient global amnesia: precipitating activities and other observations. Arch Neurol 1982;39:605-8.

12 Stevens H, Ammerman B. Transient global amnesia. Med Ann DC 1974;43:593-6.

13 Kushner HG, Hauser WA. Transient global amnesia: a casecontrol study. Ann Neurol 1985;18:684-91.

14 Hinge HH, Jensen TS, Kjaer M, Marquardsen J, de Fine Olivarius B. The prognosis of transient global amnesia. Results of a multicentre study. Arch Neurol 1986;43:673-6.

15 Nausieda P, Sherman I. Long-term prognosis in transient global amnesia. JAMA 1979;241:392-3.

16 Shuping J, Rolison R, Toole J. Transient global amnesia. Ann Neurol 1980;7:88-90.

17 Diagnostic and Statistical Manual of Mental Disorders (DSM III), 3rd ed. Washington: American Psychiatric Association, 1980.

18 Heyman A, Leviton A, Millikan CH, et al. Transient focal cerebral ischemia: epidemiological and clinical aspects. Stroke 1974; 5:277-84.

19 Miettinen OS. Estimability and estimation in case-referrent studies. Am J Epidemiol 1976;103:226-35.

20 Breslow NE, Day NE. Statistical Methods in Cancer Research. Lyons: International Agency for Research on Cancer, 1980.

21 Boissonnot L, Neau J, Rivasseau T, Gil R, Lefevre JP. Ictus amnéstique essential. Sem Hop Paris 1986;62:2357-60.

22 Miller JW, Petersen RC, Metter EJ, Millikan CH, Yanagira T. Transient global amnesia: clinical characteristics and prognosis. Neurology 1987;37:733-7.

23 Caplan LB. Transient global amnesia. In: Frederiks JAM, ed: Handbook of Clinical Neurology. Amsterdam: Elsevier Science Publisher, 1985;1:205-18.

24 Feuer D, Weinberger J. Extracranial carotid artery in patients with transient global amnesia: evaluation by real-time B-mode Ultrasonography with Duplex Doppler Flow. Stroke 1987; 18:951-3.

25 Landi G, Guidotti M, Pinciroli D, Scialfa G, Morabito A. Reversible ischemic attacks with normala ngiogram: risk factors, clinical findings and prognosis. Neurology 1985;35:412-5.

26 de Fine Olivarius B, Jensen TS. Transient global amnesia in migraine. Headache 1979;19:335-8.

27 Crowell GF, Stump DA, Biller J, McHenry LC Jr, Toole JF. The transient global amnesia-migraine connection. Arch Neurol 1984;41:75-9. 